\title{
Effects of a culturally adapted group based Montessori based activities on engagement and affect in Chinese older people with dementia: a randomized controlled trial
}

Helen Yue-lai Chan ${ }^{1 *}$, Yee-man Yau², Si-fan. Li' ${ }^{2}$ Ka-shi Kwong ${ }^{2}$, Yuen-yu Chong ${ }^{1}$, Iris Fung-kam Lee ${ }^{3}$ and Doris Sau-fung $\mathrm{Yu}^{4}$

\begin{abstract}
Background: The Montessori Method underpinned by the principle of person-centered care has been widely adopted to design activities for people with dementia. However, the methodological quality of the existing evidence is fair. The objectives of this study are to examine the feasibility and effects of a culturally adapted groupbased Montessori Method for Dementia program in Chinese community on engagement and affect in communitydwelling people with dementia.

Methods: This was a two-arm randomized controlled trial. People who were aged 60 years or over and with mild to moderate dementia were recruited and randomly assigned to the intervention group to receive Montessoribased activities or the comparison group to receive conventional group activities over eight weeks. The attendance rates were recorded for evaluating the feasibility. The Menorah Park Engagement Scale and the Apparent Affect Rating Scale were used to assess the engagement and affect during the activities based on observations. Generalized Estimating Equation model was used to examine the intervention effect on the outcomes across the sessions.

Results: A total of 108 people with dementia were recruited. The average attendance rate of the intervention group (81.5\%) was higher than that of the comparison group (76.3\%). There was a significant time-by-group intervention effect on constructive engagement in the first 10 minutes of the sessions (Wald $x^{2}=15.21-19.93$, $p s=0.006-0.033$ ), as well as on pleasure (Wald $x^{2}=25.37-25.73$, ps $\leq 0.001$ ) and interest (Wald $\times 2=19.14-$ 21.11 , ps $=0.004-0.008$ ) in the first and the middle 10 minutes of the sessions, adjusted for cognitive functioning.
\end{abstract}

Conclusions: This study provide evidence that Montessori-based group activities adapted to the local cultural context could effectively engage community-dwelling Chinese older people with mild to moderate dementia in social interactions and meaningful activities and significantly increase their positive affect.

Trial registration: ClinicalTrials.gov, NCT04352387. Registered 20 April 2020. Retrospectively registered.

Keywords: Dementia, Person-centered, Group activity, Community, Support

\footnotetext{
* Correspondence: helencyl@cuhk.edu.hk

'The Nethersole School of Nursing, Faculty of Medicine, The Chinese University of Hong Kong, Hong Kong SAR, China

Full list of author information is available at the end of the article
}

C C The Author(s). 2021 Open Access This article is licensed under a Creative Commons Attribution 4.0 International License, which permits use, sharing, adaptation, distribution and reproduction in any medium or format, as long as you give appropriate credit to the original author(s) and the source, provide a link to the Creative Commons licence, and indicate if changes were made. The images or other third party material in this article are included in the article's Creative Commons licence, unless indicated otherwise in a credit line to the material. If material is not included in the article's Creative Commons licence and your intended use is not permitted by statutory regulation or exceeds the permitted use, you will need to obtain permission directly from the copyright holder. To view a copy of this licence, visit http://creativecommons.org/licenses/by/4.0/. The Creative Commons Public Domain Dedication waiver (http://creativecommons.org/publicdomain/zero/1.0/) applies to the data made available in this article, unless otherwise stated in a credit line to the data. 


\section{Background}

Most of the people with dementia exhibit behavioural and psychological symptoms of dementia (BPSD), for example agitation, repetition, restlessness, wandering, apathy and depressed mood, resulting from cognitive impairment [1, 2]. Non-pharmacological interventions have been advocated as the first line management for addressing the modifiable factors, and thereby reducing the use of anti-psychotic or sedative medications to prevent the associated adverse effects and mortality risk, and improve the quality of life of people with dementia [3-6]. The effects of non-pharmacological interventions, for example, multisensory stimulation, cognitive or emotion-oriented interventions, behavioral management strategies, and physical exercise, have been widely studied for matching the unmet psychosocial need for sensory deprivation, social interaction and meaningful activities in people with dementia [4, 6, 7]. While systematic reviews concluded that the effects of these nonpharmacological interventions on managing challenging behaviors are inconsistent, it is widely agreed that strategies that only passively engage people with dementia have poor effects, whereas those personalized to individual needs are more promising $[1,5-7]$.

The Montessori Method has been adopted to design activities for people with dementia over the past two decades $[8,9]$. This method was originally developed by Dr Maria Montessori, a physician and educator, in the early 1900s as an educational approach for training children with functional skills for practical life challenges through sensorial experiences in the everyday environment. Montessori programming highlights task breakdown, guided repetition, progression in task difficulty from simple to complex or concrete to abstract, the careful matching of individual past interests and occupations, and self-correcting, all aligned with the concept of rehabilitation $[8,10,11]$. Dr Cameron Camp and his associates proposed the Montessori Method as a strengthbased approach for creating personalized interventions in dementia care to maximize the spared capacity and abilities of each individual [8]. The activities in the Montessori-based for dementia (MMD) program highlights the importance of considering the individual's past experiences and interests $[9,10]$. The essence of these activities is consistent with the person-centered care approach recommended for dementia care $[12,13]$. The acronym "CREATE" is used to represent the principles of activity design, they are: Create a prepared environment, Remove unnecessary distractions, Error free process, All materials are familiar to the participants in real life setting, Templates and manipulatives are provided according to individual needs and ability, and Environment is prepared in home-like. Generally speaking, the activities aim to engage participants in meaningful activities and, through which, promote learning through procedural or implicit memory with the support of prepared environment and external cues $[9,10]$. Thus far, Montessori-based activities for dementia have been conducted in a variety of formats, such as Memory Bingo or sorting pictures or words into categories, fine-motor tasks such as cutting and stringing beads, reading groups, the use of templates, and the creation and production of certain products, on an individual or group basis $[10,11]$. While activities conducted on a one-toone basis may allow more flexibility in activity design and greater attention for people with dementia, literature suggests that group format creates opportunities for people with dementia to take up meaningful social roles in the group that allow them to use their social skills, and promotes peer interaction and learning $[8,14,15]$.

Literature generally suggested that Montessori-based activities increased constructive engagement in people with dementia [3, 11, 14, 16, 17] but there were mixed results on positive and negative affect $[11,18,19]$. Moreover, the practices of conducting Montessori-based activities varied widely [3] and were mainly conducted on individual format [11]. Previous studies which examined the effects of Montessori-based activities in the Chinese people with dementia focused on agitation and were only conducted in care home setting [20,21]. Moreover, the methodological quality of these existing studies were limited by single subject design and lack of randomization $[3,11,17,19,20]$. The purposes of this study were to evaluate the feasibility of culturally adapted group-based Montessori-based activities in the Chinese communities and examine the effects of these activities on the type and level of engagement and affect of Chinese older people with mild to moderate dementia.

\section{Methods \\ Participants}

This was a multicenter two-arm parallel randomized controlled trial design conducted in three community centers, three day care centers and three care homes operated by The Salvation Army in Hong Kong between August 2018 and July 2019. The study adhered to the CONSORT guidelines. Participants were randomly assigned either the intervention group or the comparison group on 1:1 ratio by stratified randomisation based on the study site given that the health conditions of the older adults in different care settings might greatly vary. The random sequence was based on computer-generated lists using a block size of six within strata to ensure a balance allocation. A researcher who was not involved in subject recruitment and intervention design was responsible for the random allocation. The inclusion criteria were care 
recipients at the study venues aged 60 years or above, with a diagnosis of dementia at a stage 3 to 5 on the global deterioration scale (GDS) [20, 22], and were not joining any other dementia training activities. They were excluded if they presented a hazard to others through disruptive behaviors or proxy consent could not be obtained. The sample size was estimated based on the level of constructive engagement during the activity. According to Judge et al.'s study (2000) [14], the effect size of the Montessori-based activities in people with dementia were approximately 1.5 . With an estimated $20 \%$ attrition rate, 18 participants will be needed for each arm for a two-sided test with a Type I error of 0.05 at $80 \%$ power. The overall sample size was 108 , with a subsample of 36 participants from each type of setting given the context of the three types of care settings may vary.

\section{Description of the intervention}

Participants in the intervention group received MMD program whereas participants in the comparison group received conventional group activities provided at the study venues on different days over eight weeks. All sessions were conducted in group format with about six participants per group for one hour. The group format created opportunities for participants to express their social skills during the activities [12]. The program design covered five aspects, namely cognitive stimulation, life skills, motor movements and fitness, sensory stimulation, and socialization. Each 1-hour session included two to three activities tailored to the local cultural context. A standardized manual and activity materials were developed to ensure the treatment fidelity. The program was delivered by staff who had completed certified training in Montessori-based activities. Participants in the comparison group received activities delivered regularly in the usual care, such as reading out newspapers, physical activities, and watching videos, in the sessions delivered by staff members who were blinded to the study design and had not received training in Montessori-based activities.

\section{Study outcomes}

The primary outcome was type and level of engagement and the secondary outcome was affect during the activities. Observations were conducted on the individual participant for a ten-minute period at the beginning, middle, and end of the activity of each session. The Menorah Park Engagement Scale (MPES) was used to measure engagement in terms of constructive engagement, passive engagement, non-engagement and other engagement in activities [14]. The level of engagement was determined based on observation and rated on a three-point Likert scale, from $0=$ not at all observed to
$2=$ equal or more than half of the observed time. MPES was found to be sensitive to measure the effects of activity programming of Montessori-based activities [23]. The Apparent Affect Rating Scale (AARS) was used to measure five positive and negative affect, including pleasure, anger, anxiety/fear, depression/sadness, and interest, through observation [24]. Each affect was measured on a five-point Likert scale, from $1=$ never to $5=$ more than five minutes. It is a valid and reliable measure of affect in care home residents with dementia and has been used to measure Montessori-based activities in previous studies [11]. Demographic data, including age, sex, level of GDS and score of Montreal Cognitive Assessment (MoCA), were collected at baseline.

\section{Data collection}

Ethical approval for the study was obtained from the Survey and Behavioural Ethics Committee of The Chinese University of Hong Kong (no reference number is available). Staff members of the participating venues initially screened all the clients and approached the designated family member of the potential participants for recruitment. Proxy consent to participate in the study was obtained in a written format from the family member who was the primary carer of the care recipients who met the study inclusion criteria. They were asked to provide consent of allowing their relatives with dementia, i.e. the potential participants, to participate in either the MMD program or the usual activities as scheduled and being videotaped during the sessions to facilitate observation of their reactions and behaviours. In addition to verbal explanation, an information sheet about the study purpose and the nature of the data collection were provided for consideration. All data were coded and used on an anonymous basis. All sessions were videotaped for research purpose only to facilitate assessment and were not disclosed or shared publicly. Assent to join the activities was also obtained from the potential participants each time before the session. Participation was voluntary. Two research assistants with psychology backgrounds and blinded to the group allocation watched the videos independently to conduct the observations. They record the length of time for the different types of engagement and affect exhibited by each participant during the session. Training on the data collection was provided. The inter-rater reliability in study outcomes was established with over $90 \%$ agreement for $30 \mathrm{ob}$ servations between the research assistants to ensure consistency of assessment. Attendance record were kept for all sessions to evaluate the feasibility. A phone follow up was conducted after each session with those who were absent to clarify the reasons. 


\section{Statistical analysis}

The intention to treat principle was applied in the analysis [25]. Descriptive statistics were used to summarize the participants' socio-demographic data, cognitive state and the study outcomes. Independent $t$ test and Chi-square test were used to compare the homogeneity between the intervention group and the comparison group at baseline, as appropriate. A Generalized Estimating Equation model was used to examine the intervention effect on the study outcomes between groups across eight sessions, adjusting for covariates. SPSS (version 25.0 IBM, Armonk, NY, US) was used for the statistical analysis.

\section{Results}

\section{Participants' characteristics}

As shown in Fig. 1, a total of 147 participants were screened for eligibility for the study. Of the 122 potential participants, 108 participated in the study. The major reasons for not participating in the study were lack of interest in the study, inability to attend the sessions due to mobility problems or a lack of escort services, and inability to obtain proxy consent from family members. Table 1 shows the participants' characteristics. Their mean age was 83.9 (SD 7.0) years, ranging from 67 to 99 . Female participants accounted for $71.0 \%$ of the total. No significant differences in the demographic and clinical characteristics were observed between the two groups at baseline.

\section{Feasibility}

The mean attendance rate of the sessions was $79.1 \%$. The average attendance rate of the intervention group $(81.5 \%)$ was higher than that of the comparison group (76.3\%), but the difference was not statistically significant. The common reasons for non-attendance were time clash with medical appointment (11.1\%), not interest in the activities (7.4\%), change in health condition and hospitalization $(2.8 \%)$.

\section{Engagement}

The effects of MMD program on the types and levels of engagement between the intervention group and the comparison group across the treatment sessions is shown in Table 2. The intervention group was found to have a significantly higher level of constructive engagement in the first 10 minutes of each session (Wald chisquare $=15.2, p=0.033)$ and in the middle 10 minutes of each session (Wald chi-square $=19.9, p=0.006$ ), as well as lower level of passive engagement in the last 10 minutes of each session (Wald chi-square $=17.61$, $p=0.014$ ) across the study period, after adjusting for MoCA score and GDS score. Subgroup analysis

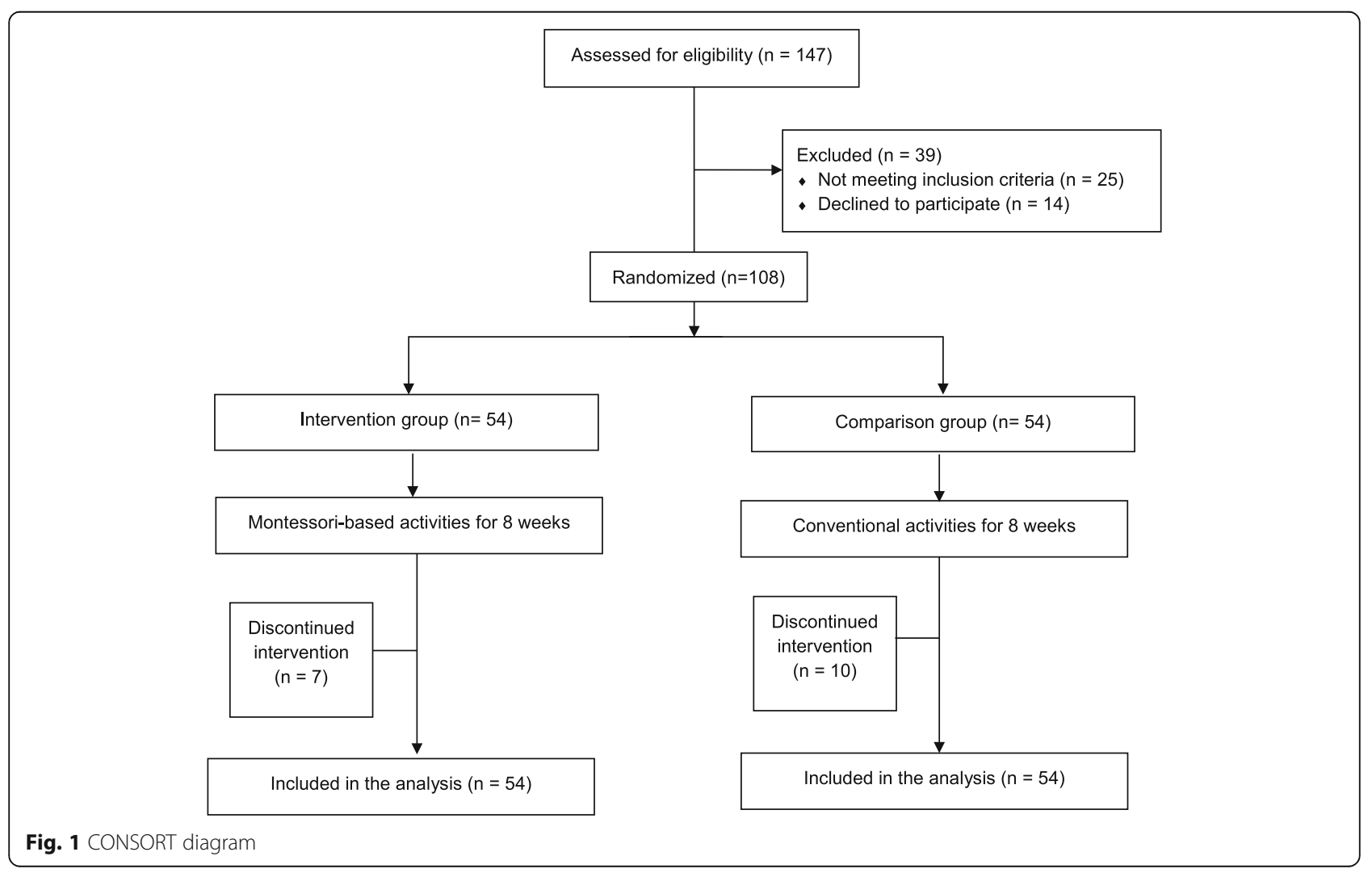


Table 1 Participants' characteristics

\begin{tabular}{|c|c|c|c|}
\hline & Comparison Group $(n=54)$ & $\begin{array}{l}\text { Intervention } \\
\text { Group }(n=54)\end{array}$ & $p$ value $^{*}$ \\
\hline$\overline{\text { Age (years), mean (SD) }}{ }^{a}$ & $84.5(6.5)$ & $83.3(7.5)$ & 0.363 \\
\hline $\begin{array}{l}\text { Sex, n (\%) } \\
\text { Male } \\
\text { Female }\end{array}$ & $\begin{array}{l}16(29.6) \\
38(70.4)\end{array}$ & $\begin{array}{l}17(31.5) \\
37(68.5)\end{array}$ & 0.828 \\
\hline Global Deterioration Scale, $n(\%)$ & & & 0.270 \\
\hline Stage 3 & $5(9.3)$ & $4(7.4)$ & \\
\hline Stage 4 & $32(59.3)$ & $35(64.8)$ & \\
\hline Stage 5 & $17(31.5)$ & $15(27.8)$ & \\
\hline MoCA scores, mean (SD)a & $8.9(5.0)$ & $9.1(5.5)$ & 0.882 \\
\hline
\end{tabular}

revealed no differences between participants in the community care and those in the care home settings.

\section{Affect}

Only two aspects of affect measured by the AARS, pleasure and interest, were included in the analysis because anxiety/fear and sadness were rarely observed. As shown in Table 3, there was a significant time-by-group intervention effect on pleasure in the first 10 minutes of each session (Wald chi-square $=25.4, p<0.001$ ) and in the middle 10 minutes of each session (Wald chi-square $=$ 25.7, $p<0.001)$ across the entire session period, as well as on interest in the first 10 minutes of each session (Wald chi-square $=21.1, p=0.004$ ) and in the middle 10 minutes of each session (Wald chi-square $=19.1, p=$ 0.008 ), by adjusting the MoCA score and the GDS score. No differences were noted between participants in the community care and those in the care home settings in the subgroup analysis.

\section{Discussion}

This study evaluates the feasibility and effectiveness of a culturally adapted group based MMD program on engagement and affect in older people with mild to moderate dementia in the Chinese communities. MMD program is a strength-based approach intervention highlighting the importance of tailoring personalized activities according to individual's interests and abilities $[3,8,9]$. The experience from this study suggested that the Montessori-based activities were acceptable to the community-dwelling Chinese older people with dementia in both the community care setting and care home setting. Participants in the intervention group exhibited more constructive engagement during the activities than did the comparison group. Also, less passive engagement was observed in the intervention group compared to the comparison group. These findings echo the findings of previous studies that higher level of constructive engagement and lower level of passive engagement or non-engagement were observed during Montessoribased activities [3, 14, 18, 26]. This study confirms that the personalized activities adapted to the local cultural context could increase constructive engagement and reduce passive engagement among people with dementia in Chinese communities [5, 13].

The findings also suggest that the MMD program increase positive affect in older Chinese people with mild to moderate dementia. Higher levels of pleasure and interest were observed during the Montessoribased activities in the intervention group across sessions than the conventional activities in the comparison group. This is consistent with previous studies that Montessori based activities conducted on individual basis can increase positive affect and interest in people with dementia $[11,19,26]$. This study demonstrated that the Montessori-based activities in a small group format is also effective in increasing positive affect in people with dementia. Lin and associates (2009) compared the effects of Montessori-based activities with acupressure noted that the increased in positive affect in participants joining the Montessoribased activities may be due to the social nteractions among group members during the activities [27].

Despite the merits of the MMD program, more preparatory works and manpower was needed compared with other conventional activities as the staff members need to explore the uniqueness of each individual and maintain close observation so as to modify the activity or materials to meet individual's characteristics and group dynamics. We acknowledged several study limitations when interpreting the findings. First, this study included a small sample size from community care and care home settings. Further research should include a larger sample size to increase the generalizability of the findings. Second, the study outcomes concerned about the participants' engagement and affect reflected the immediate effects of the intervention only. Follow-up 
Table 2 Effects of MMD program versus usual care on the MPES scores across treatment sessions

\begin{tabular}{|c|c|c|c|c|c|c|}
\hline \multirow[t]{2}{*}{ Measures } & \multicolumn{2}{|c|}{ Time effect } & \multicolumn{2}{|c|}{ Group effect } & \multicolumn{2}{|c|}{ Time-by-group effect } \\
\hline & Wald $x^{2}$ & $p$ & Wald $x^{2}$ & $p$ & Wald $x^{2}$ & $p$ \\
\hline \multicolumn{7}{|c|}{ Constructive engagement } \\
\hline \multicolumn{7}{|c|}{ At the beginning 10 minutes of the session } \\
\hline Intervention group & 28.75 & $<0.001^{* * *}$ & 20.07 & $<0.001^{* * *}$ & 15.21 & $0.033^{*}$ \\
\hline \multicolumn{7}{|l|}{ Comparison group } \\
\hline \multicolumn{7}{|c|}{ At the middle 10 minutes of the session } \\
\hline Intervention group & 13.26 & $<0.001^{* * *}$ & 30.15 & $<0.001^{* * *}$ & 19.93 & $0.006^{* *}$ \\
\hline \multicolumn{7}{|l|}{ Comparison group } \\
\hline \multicolumn{7}{|c|}{ At the last 10 minutes of the session } \\
\hline Intervention group & 2.79 & NS & 36.94 & $<0.001^{* * *}$ & 3.54 & 0.831 \\
\hline
\end{tabular}

Comparison group

\section{Passive engagement}

At the beginning 10 minutes of the session

Intervention group

$0.003^{* *}$

0.41

NS

5.40

Comparison group

At the middle 10 minutes of the session

Intervention group 234

NS

4.79

$0.029^{*}$

7.96

0.336

Comparison group

At the last 10 minutes of the session

Intervention group

7.56

NS

9.45

$0.002^{* *}$

17.61

$0.014^{*}$

Comparison group

\section{Non-engagement}

At the beginning 10 minutes of the session

Intervention group

7.28

NS

7.28

$0.007^{* *}$

8.67

0.277

Comparison group

At the middle 10 minutes of the session

Intervention group

4.65

NS

7.26

$0.007^{* *}$

2.04

0.958

Comparison group

At the last 10 minutes of the session

Intervention group

11.17

NS

6.43

$0.011^{*}$

5.32

0.621

Comparison group

\section{Other engagement}

At the beginning 10 minutes of the session

Intervention group

15.30

$0.032^{*}$

2.45

NS

9.27

0.234

Comparison group

At the middle 10 minutes of the session

Intervention group

13.30

NS

0.16

NS

12.32

0.090

Comparison group

At the last 10 minutes of the session

Intervention group

7.90

NS

0.65

NS

12.44

0.087 
Table 3 Effects of MMD Program versus usual care on AARS scores across treatment sessions

\begin{tabular}{|c|c|c|c|c|c|c|}
\hline \multirow[t]{2}{*}{ Measures } & \multicolumn{2}{|c|}{ Time effect } & \multicolumn{2}{|c|}{ Group effect } & \multicolumn{2}{|c|}{ Time-by-group effect } \\
\hline & Wald $x^{2}$ & $p$ & Wald $x^{2}$ & $p$ & Wald $x^{2}$ & $p$ \\
\hline \multicolumn{7}{|l|}{ Pleasure } \\
\hline \multicolumn{7}{|c|}{ At the beginning 10 minutes of the session } \\
\hline Intervention group & 13.08 & NS & 20.97 & $<0.001^{* * *}$ & 25.37 & $<0.001^{* * *}$ \\
\hline \multicolumn{7}{|l|}{ Comparison group } \\
\hline \multicolumn{7}{|c|}{ At the middle 10 minutes of the session } \\
\hline Intervention group & 7.34 & NS & 35.19 & $<0.001^{* * *}$ & 25.73 & $<0.001^{* * *}$ \\
\hline \multicolumn{7}{|l|}{ Comparison group } \\
\hline \multicolumn{7}{|c|}{ At the last 10 minutes of the session } \\
\hline Intervention group & 3.41 & NS & 33.51 & $<0.001^{* * *}$ & 13.18 & NS \\
\hline \multicolumn{7}{|l|}{ Comparison group } \\
\hline \multicolumn{7}{|l|}{ Interest } \\
\hline \multicolumn{7}{|c|}{ At the beginning 10 minutes of the session } \\
\hline Intervention group & 16.92 & NS & 8.56 & $0.003^{* *}$ & 21.11 & $0.004^{* *}$ \\
\hline \multicolumn{7}{|l|}{ Comparison group } \\
\hline \multicolumn{7}{|c|}{ At the middle 10 minutes of the session } \\
\hline Intervention group & 9.52 & NS & 1.19 & NS & 19.14 & $0.008^{* *}$ \\
\hline \multicolumn{7}{|l|}{ Comparison group } \\
\hline \multicolumn{7}{|c|}{ At the last 10 minutes of the session } \\
\hline Intervention group & 12.94 & NS & 1.89 & NS & 11.09 & NS \\
\hline Comparison group & & & & & & \\
\hline
\end{tabular}

Note: Generalized estimating equation; Wald $x^{2}=$ Wald Chi-square; NS not significant; ${ }^{*} p<0.05,{ }^{* *} p<0.01,{ }^{* * *} p<0.001$

assessment over a longer period is warranted to examine the sustained effects of the program. Third, the influence of other socio-demographic factors on the study outcomes were not examined. In addition, assessment about its effects on the participants' cognitive functioning and behaviors beyond the group sessions, and costs related to the intervention implementation should also be explored in future studies.

\section{Conclusions}

This study used a robust study design to evaluate the effects of a culturally specific Montessori-based activities in Chinese community-dwelling older people with mild to moderate dementia. The design of these activities valued individual's past experiences and present abilities, highlighting the importance of person-centered care. The evidence supports that such approach is feasible and effective in increasing the level of engagement and positive affect of people with dementia through meaningful activities and social interactions.

\section{Abbreviations}

AARS: Apparent Affect Rating Scale; MMD: Montessori Method for Dementia; GDS: Global Deterioration Scale; MPES: Menorah Park Engagement Scale; MoCA: Montreal Cognitive Assessment

\section{Acknowledgements}

We are grateful to Hong Kong Occupational Therapy Association for providing training to the staff members and all the participants for their support to the study. We would also like to thank Mr Alston Chung and Ms Kathy Chan in assisting with data collection.

\section{Authors' contributions}

$\mathrm{HC}, Y Y, S L, K K, I L$ and DY conceptualized the study. HC, YY and KK supported the data collection. HC, YY, SL, KK and YC analyzed and interpret the data. $\mathrm{HC}$ and $\mathrm{YC}$ drafted the manuscript. All authors critically reviewed the paper and approved the final manuscript.

\section{Funding}

This study was supported by Phase III Social Welfare Development Fund, Social Welfare Department, The Hong Kong SAR Government. The content is solely the responsibility of the authors. The funding body has no role in the design of the study and collection, analysis, and interpretation of data and in writing the manuscript.

\section{Availability of data and materials}

The datasets used and/or analysed during the current study are available from the corresponding author on reasonable request.

\section{Ethics approval and consent to participate}

The study was approved by the Survey and Behavioural Research Ethics Committee of The Chinese University of Hong Kong. All participation was on voluntary basis and proxy written consent was obtained from the family members of the peoples with dementia.

Consent for publication

The manuscript does not contain any individual person's data. 


\section{Competing interests}

The authors declare that they have no conflict of interests.

\section{Author details}

'The Nethersole School of Nursing, Faculty of Medicine, The Chinese University of Hong Kong, Hong Kong SAR, China. ${ }^{2}$ Social Services Department, The Salvation Army, Hong Kong and Macau Command, Hong Kong SAR, China. ${ }^{3}$ Nethersole Institute of Continuing Holistic Health Education, Hong Kong SAR, China. ${ }^{4}$ School of Nursing, Faculty of Medicine, The University of Hong Kong, Hong Kong SAR, China.

Received: 20 April 2020 Accepted: 16 December 2020

Published online: 07 January 2021

\section{References}

1. ljaopo EO. Dementia-related agitation: a review of non-pharmacological interventions and analysis of risks and benefits of pharmacotherapy. Trans Psychiatry. 2017;7(10):e1250. Available from: https://doi.org/10.1038/tp.2017. 199

2. Feast A, Orrell M, Charlesworth G, Melunsky N, Poland F, Moniz-Cook E. Behavioural and psychological symptoms in dementia and the challenges for family carers: Systematic review. Br J Psychiatry. 2016;208(5):429-34.

3. Hitzig SL, Sheppard CL. Implementing Montessori Methods for Dementia: A Scoping Review. Gerontologist. 2017;57(5):e94-114.

4. Livingston G, Kelly L, Lewis-Holmes E, Baio G, Morris S, Patel N, et al. Nonpharmacological interventions for agitation in dementia: Systematic review of randomised controlled trials. Br J Psychiatry. 2014;205(6):436-42.

5. Chalfont $\mathrm{G}$, Milligan C, Simpson J. A mixed methods systematic review of multimodal non-pharmacological interventions to improve cognition for people with dementia. Dementia. 2020;19(4):1086-130.

6. Dyer SM, Harrison SL, Laver K, Whitehead C, Crotty M. An overview of systematic reviews of pharmacological and non-pharmacological interventions for the treatment of behavioral and psychological symptoms of dementia. Int Psychogeriatrics. 2018;30(3):295-309.

7. Abraha I, Rimland JM, Trotta FM, Dell'Aquila G, Cruz-Jentoft A, Petrovic M, et al. Systematic review of systematic reviews of non-pharmacological interventions to treat behavioural disturbances in older patients with dementia. the SENATOR-OnTop series. BMJ Open. 2017;7:3.

8. Camp CJ. Origins of Montessori Programming for Dementia. Nonpharmacl Ther Dement. 2010;1(2):163-74.

9. Bourgeois MS, Brush J, Elliot G, Kelly A. Join the Revolution: How Montessor for Aging and Dementia can Change Long-Term Care Culture. Semin Speech Lang. 2015;36(3):209-14.

10. Malone ML, Camp CJ. Montessori-based dementia programming: Providing tools for engagement. Dementia. 2007:6(1):150-7.

11. Sheppard CL, McArthur C, Hitzig SL. A Systematic Review of MontessoriBased Activities for Persons With Dementia. J Am Med Dir Assoc. 2016;17(2): 117-22.

12. Kogan AC, Wilber K, Mosqueda L. Person-Centered Care for Older Adults with Chronic Conditions and Functional Impairment: A Systematic Literature Review. J Am Geriatr Soc. 2016;64(1):e1-7.

13. McCormack B, McCance TV. Development of a framework for personcentred nursing. J Adv Nurs. 2006;56(5):472-9.

14. Judge KS, Camp CJ, Orsulic-jeras S. Use of Montessori-based activities for clients with dementia in adult day care: Effects on engagement. Am J Alzheimers Dis Other Demen. 2000;15(1):42-6.

15. Ducak K, Denton M, Elliot G. Implementing Montessori Methods for Dementia ${ }^{\mathrm{TM}}$ in Ontario long-term care homes: Recreation staff adn multidisciplinary consultants' perceptions of policy and practice issues. Dementia. 2018;17(1):5-33.

16. Cartwright J, Oliver E. What 's the evidence ? Montessori-based interventions for people with dementia in a residential aged-care setting. $J$ Clin Pract Speech-Language Pathol. 2015;17(2):94-7.

17. Lee MM, Camp CJ, Malone ML. Effects of intergenerational Montessoribased activities programming on engagement of nursing home residents with dementia. Clin Interv Aging. 2007;2(3):477-83.

18. Jarrott SE, Gozali T, Gigliotti CM. Montessori programming for persons with dementia in the group setting: An analysis of engagement and affect. Dementia. 2008:7(1):109-25.
19. Giroux D, Robichaud L, Paradis M. Using the Montessori approach for a clientele with cognitive impairments: A quasi-experimental study design. Int J Aging Hum Dev. 2010;71(1):23-41.

20. Yuen I, Kwok T. Effectiveness of DementiAbility Methods: The Montessori Way on agitation in long-term care home residents with dementia in Hong Kong. Int J Geriatr Psychiatry. 2019;(June 2018):1-7.

21. Chen KM, Chen MH, Chao HC, Hung HM, Lin HS, Li CH. Sleep quality, depression state, and health status of older adults after silver yoga exercises: cluster randomized trial. Int J Nurs Stud. 2009;46(2):154-63.

22. Reisberg B, Ferris S, de Leon M, Crook T. The global deterioration scale for assessment of primary degenerative dementia. Am J Psychiatry. 1982;139(9): $1136-9$

23. Judge KS, Camp CJ, Orsulic-jeras S. Use of Montessori-based activities for clients with dementia in adult day care: Effects on engagement. Am J Alzheimer's Dis. 2000;15(1):42-6.

24. Lawton P, VanHaitsma K, Perkinson M, Ruckdeschel K. Observed affect and quality of life in dementia: Further affirmations and problems. J Ment Health Aging. 1999;5(1):69-81.

25. McCoy CE. Understanding the intention-to-treat principle in randomized controlled trials. West J Emerg Med. 2017;18(6):1075-8.

26. van der Ploeg ES, Eppingstall B, Camp CJ, Runci SJ, Taffe J, O'Connor DW. A randomized crossover trial to study the effect of personalized, one-to-one interaction using Montessori-based activities on agitation, affect, and engagement in nursing home residents with Dementia. Int Psychogeriatrics. 2013;25(4):565-75

27. Lin LC, Yang MH, Kao CC, Wu SC, Tang SH, Lin JG. Using acupressure and Montessori-based activities to decrease agitation for residents with dementia: A Cross-over trial. J Am Geriatr Soc. 2009:57(6):1022-9.

\section{Publisher's Note}

Springer Nature remains neutral with regard to jurisdictional claims in published maps and institutional affiliations.

Ready to submit your research? Choose BMC and benefit from:

- fast, convenient online submission

- thorough peer review by experienced researchers in your field

- rapid publication on acceptance

- support for research data, including large and complex data types

- gold Open Access which fosters wider collaboration and increased citations

- maximum visibility for your research: over $100 \mathrm{M}$ website views per year

At $\mathrm{BMC}$, research is always in progress.

Learn more biomedcentral.com/submissions 